\title{
Differentiation of Palaeogene sand by glauconitic and geochemical fingerprinting, Siri Canyon, Danish North Sea
}

\author{
Mette Olivarius, Christian Knudsen and Johan B. Svendsen
}

The submarine Siri Canyon is NE-SW-oriented and located in the Danish North Sea (Fig. 1). It contains a number of oil reservoirs with glauconite-rich sand. The reservoirs of interest in the Nini oil field are the Late Paleocene Tyr Member of the Lista Formation and the Kolga Member of the Sele Formation (Schiøler et al. 2007), presumably of Early Eocene age. These members have previously been known as the Ty and Hermod members (Hamberg et al. 2005; Poulsen et al. 2007). The sand shows signs of injection, both in cores and in seismic data. The aim of this work is to chemically characterise and fingerprint the sand in order to reveal the origin of the sand found in three horizontal wells, which could have been injected from one or both of the Tyr and Kolga members. Core samples were collected from two vertical wells of known stratigraphy to make a basis of comparison, whereas samples of the cuttings were collected from the three horizontal wells with ages primarily corresponding to the Kolga Member. The purpose was moreover to evaluate whether cuttings samples can be used for fingerprinting as an alternative to core samples.

The interest in discriminating between the ages of the injected sand is the fact that the reservoir properties (porosity and permeability) are largely controlled by the original composition of the sand. Consequently, results from this study could affect the property modelling of the field.

Sand from the Tyr and Kolga members is dominated by quartz and glauconite and contains fairly well-preserved Kfeldspar, plagioclase and mica. The content of feldspar and mica is quite constant, and the feldspar and quartz grains are equally rounded. K-feldspar is more common and better preserved than plagioclase, and K-feldspar overgrowth is often found on plagioclase grains. Barite and siderite are important authigenic phases in several intervals, but the presence of barite may be due to the use of drilling mud, potentially contaminating the sand samples with both barium and strontium. Most of the sand is fairly loose, but parts of the Tyr Member are cemented by quartz and calcite as it was located below the oil-water contact, whereas cementation was largely inhibited by oil in most of the Kolga Member.

\section{Methods}

Geochemical analyses were performed using a number of methods including inductively coupled plasma mass spectrometry (ICP-MS). The advantages of this method compared with X-ray fluorescence (XRF) are that the former measures a wider range of trace elements including rare-earth elements (REE), and that the detection limits are lower than those of XRF, which allows more accurate interpretation of elements found in low concentrations. Core material has previously been analysed by Friis et al. (2007) using XRF.

The modal composition of the sand as well as the chemical composition of the individual mineral grains have been analysed using computer-controlled scanning electron microscopy (CCSEM), where each grain is classified as a specific mineral on the basis of its chemical composition (Keulen et al. 2008). This method was applied in order to discern whether the samples could be differentiated based on their glauconite composition and to test if injected sand could be identified by its glauconite composition. The $>45 \mu \mathrm{m}$ fraction of the sand was used for the analyses. Oil was extracted by toluene, and detergent applied to remove the oily drilling mud and disintegrate the slightly lithified sand.

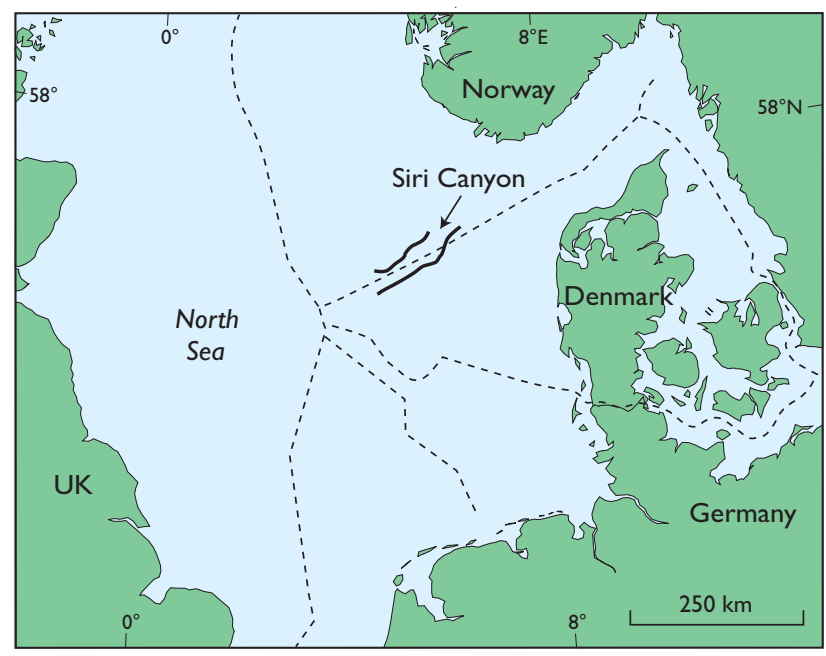

Fig. 1. Map of the North Sea region showing the location of the NE-SWoriented Siri Canyon with the Tyr and Kolga members under investigation in the Nini oil field. Dashed lines: national borders. 

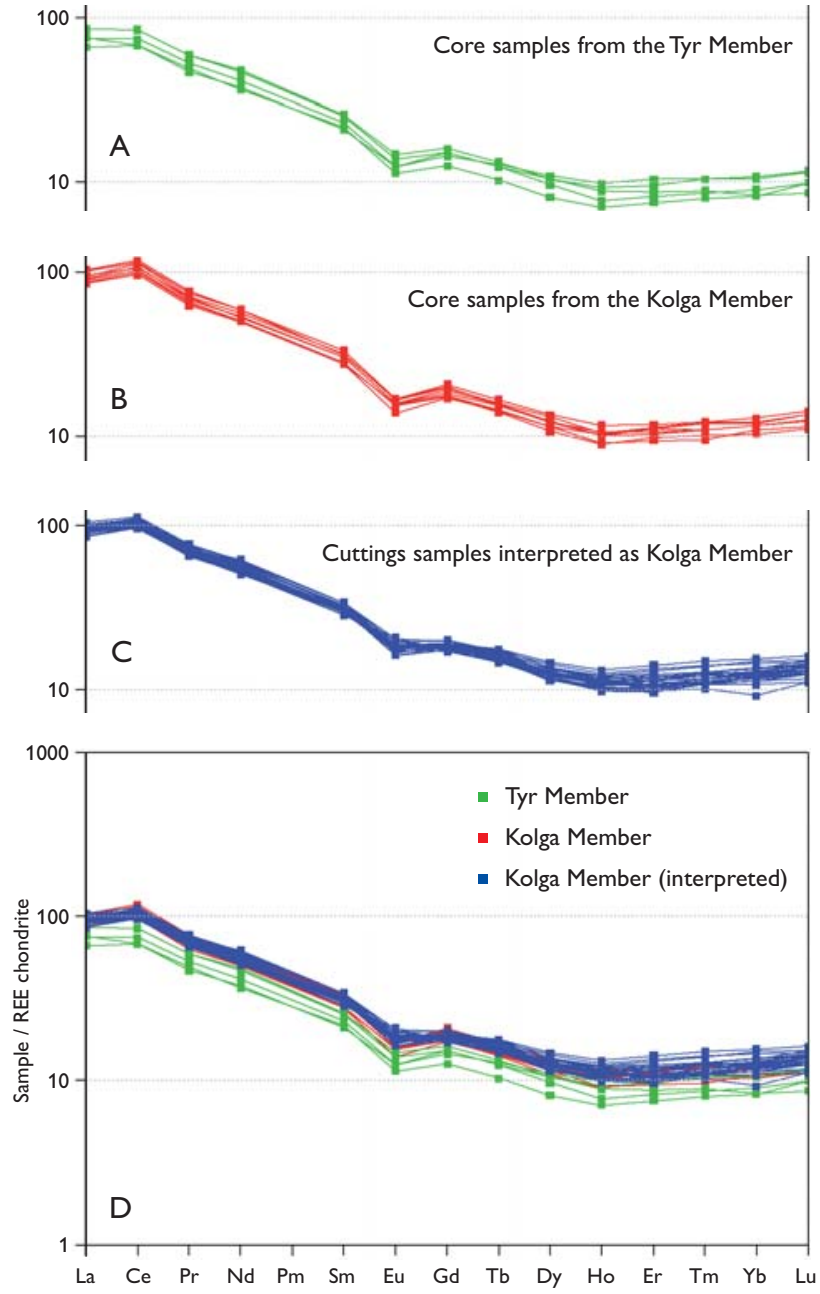

Fig. 2. REE spectra measured by ICP-MS and normalised to the chondrite composition of Boynton (1984). A: The Tyr Member has lower REE concentrations than the Kolga Member. B: The Kolga Member is characterised by a small positive cerium anomaly. C: REE spectra from cuttings samples from intervals without infiltration by drilling mud or clayey deposits and with normal resistivity. D: Composite diagram with REE spectra from $\mathrm{A}, \mathrm{B}$ and $\mathrm{C}$ indicating that the known and interpreted intervals of the Kolga Member are idential and that they are different from those of the Tyr Member.

Bulk geochemical analyses were carried out at AcmeLabs, Vancouver, on 14 core samples and 73 cuttings samples. Major and several minor elements were determined by inductively coupled plasma emission spectrometry (ICP-ES) on fused glass discs, whereas trace elements, including REE, were identified by ICP-MS also on fused glass discs.

The modal content of minerals in 10 core samples and 16 samples of the cuttings mounted in epoxy were determined at GEUS by CCSEM on a Philips XL40SEM (Keulen et al. 2008). Approximately 1200 grains were analysed per sample. The method integrates backscattered electron micro- graphs with energy dispersive X-ray spectrometry (EDX) to measure the element composition of each grain. The major element weight percentages ( $\mathrm{wt} \%$ ) were measured as oxides. The analysis is performed by sweeping over the entire grain, and hence the chemical analysis represents an average of the whole grain and not a point. This is important because the glauconite grains are inhomogeneous. Grain size and shape parameters were also measured at the cut surface in the polished section. The fragile nature of the glauconite grains made crushing of the more consolidated parts of the sand inexpedient, so a new application of the CCSEM method was developed with measurement of chemical composition in points defined by a grid. This was done in five additional core samples.

\section{Geochemistry}

Chondrite-normalised REE spectra of the Tyr and Kolga members are quite similar (Fig. 2), except for a positive cerium anomaly in the Kolga Member. The REE concentrations are moreover higher in the Kolga Member. The REE spectra of the cuttings samples fit very well with the Kolga Member (Fig. 2D). However, the wells from which the cuttings were sampled have some intervals with high resistivity, and these are generally characterised by a lower content of cerium and an enlarged negative europium anomaly.

The lower content of trace elements in the Tyr Member than in the Kolga Member makes the sand distinguishable by a number of factors. For example, Th and Ce in the Tyr Member are below 6 ppm and 70 ppm, respectively, whereas the concentration is higher in the Kolga Member. All samples of the cuttings except four are, on this basis, interpreted as Kolga Member. The four outliers are diluted by either calcite cementation or organic matter, which is seen as high values of calcium and loss on ignition (LOI), respectively.

\section{Glauconite composition}

The glauconite grains show a wide range in chemical composition, which is reflected in green to brown colours. Green grains are usually rounded and well preserved, whereas brown grains show some structural and chemical resemblance to clay minerals. The roundness of the grains could either be caused by their formation process or by subsequent physical abrasion (Odin \& Matter 1981). The best preserved grains are usually those with the highest iron content. Zonation seen in many glauconite grains with light centres and dark rims is apparently related to outward decreasing magnesium content. 

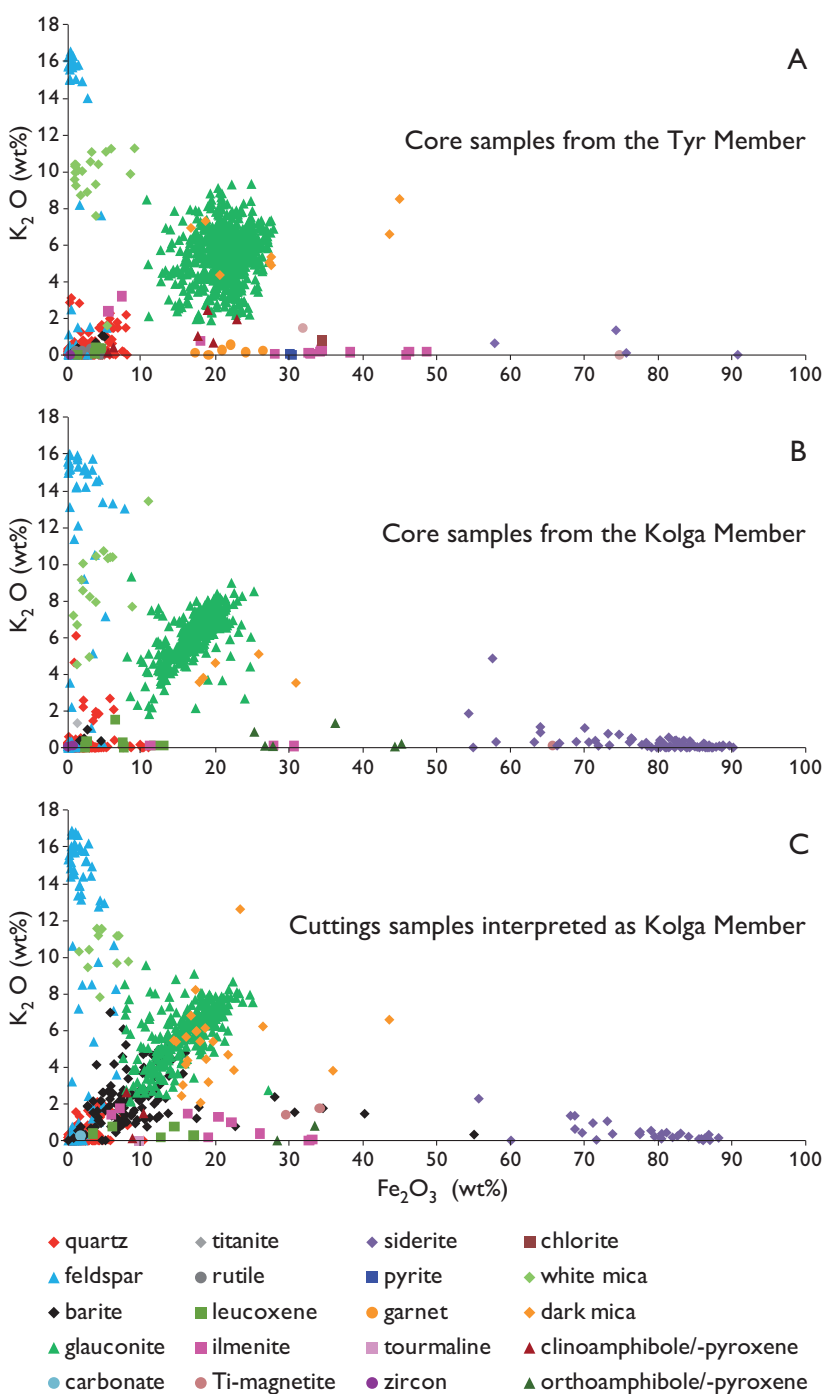

Fig. 3. Fe-K composition of the minerals expressed as $\mathrm{Fe}_{2} \mathrm{O}_{3}$ versus $\mathrm{K}_{2} \mathrm{O}$ measured by CCSEM. A: The Tyr Member shows a broad glauconite composition without a linear trend. B: The Kolga Member is characterised by a narrow glauconite composition. C: The sand from the cuttings samples has a glauconite composition that closely resembles that of the Kolga Member.

Compositional variation is recorded in the glauconite in every sample. However, this variation range is different in the Tyr and Kolga members. The glauconite in core samples from the Tyr Member is characterised by a broad scatter and high iron content (Fig. 3A), which is distinctly different from the glauconite of the Kolga Member. The Kolga Member shows positive correlation between iron and potassium (Fig. 3B), which represents a substitution series with aluminium. The Kolga Member is moreover distinguishable by a high siderite content compared to the Tyr Member. All the cuttings samples of unknown stratigraphy are interpreted as Kolga Mem-
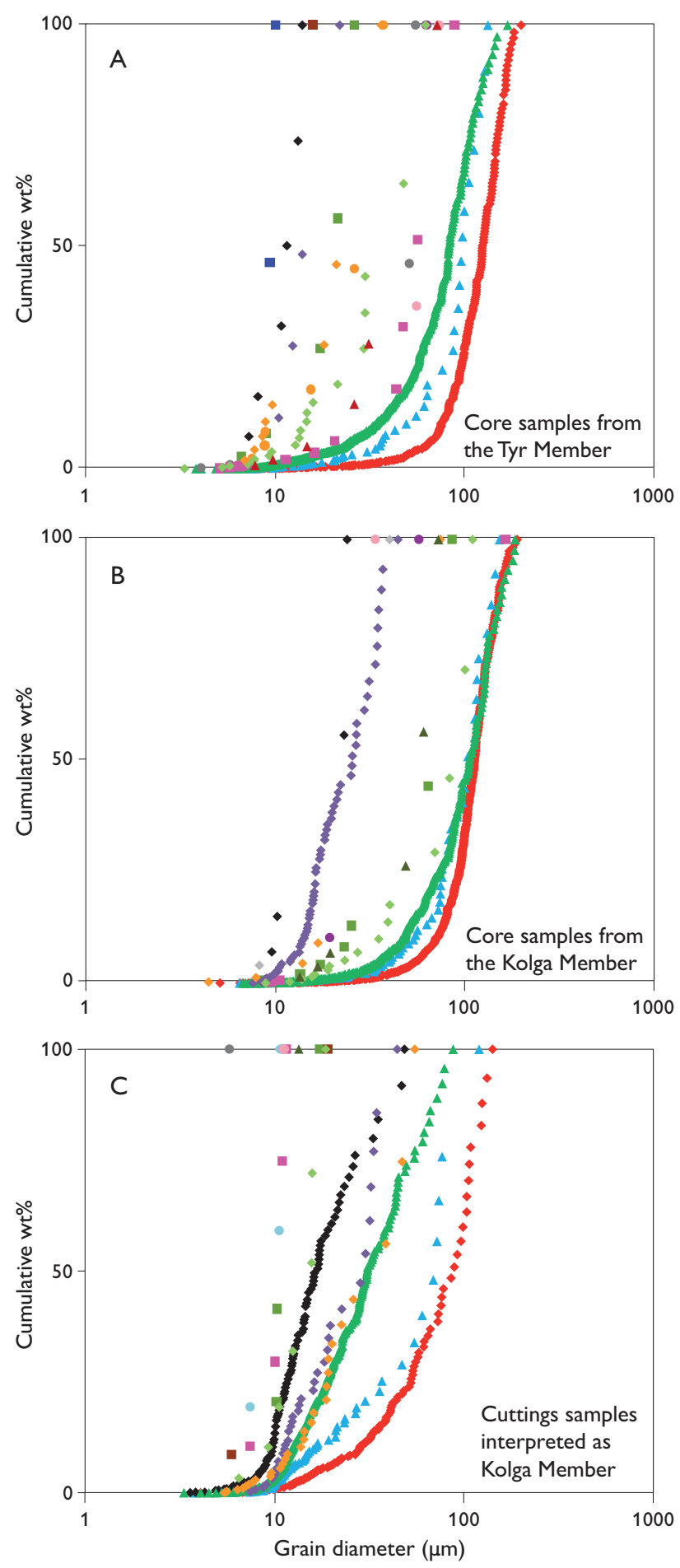

Fig. 4. Grain-size distribution curves for the minerals measured by CCSEM. A: The grain-size distribution of the Tyr Member has only been measured in one sample, where the glauconite shows a smaller grain size than quartz. B: Quartz and glauconite grains in the Kolga Member are of medium size. C: The cuttings samples have undergone severe crushing and hence the origin of the sand is difficult to determine from the grain-size distribution alone. For legend see Fig. 3. 
ber on the basis of mineralogy, as their glauconite compositions and siderite contents fit well with this sand (Fig. 3C).

A large amount of barite is found in many of the cuttings samples, but at least some of it comes from the drilling mud. Five of the six samples from the cored Tyr Member have been measured in single points instead of whole grains because of the extensive cementation, so the results are not entirely reliable. However, the measured glauconite compositions fit well with the broad scatter measured in the un-cemented sample.

\section{Grain curves}

The quartz of both the Tyr and Kolga members is well-sorted, and the variation in grain-size distributions is small (Fig. 4). The heavy minerals are finer grained than the light minerals, showing that hydraulic sorting has occurred. The average grain size of the glauconite and quartz grains is almost equal in the Kolga Member, but the sorting of glauconite is poorer than quartz due to a broad, fine-grained tail, which may be caused by crushing of the fragile glauconite grains. The glauconite in the Kolga Member is coarser grained than in the Tyr Member. However, the grain size of the Tyr Member has only been measured in one sample because of the cementation in the other samples. Siderite is silt-sized, and the almost straight grain curves in most samples show that the siderite is authigenic (Weibel et al. 2010).

Cores and cuttings are dominated by quartz grains of about the same size (Fig. 4), but the cuttings also contain a fine-grained tail (Fig. 4C) which may have been generated by crushing during the drilling process. The glauconite grains are especially susceptible to crushing because of their fragile nature, and this explains why glauconite from cuttings samples is more fine grained than from core samples.

\section{Concluding remarks}

The samples of the cuttings collected from the horizontal wells are interpreted as Kolga Member on the basis of trace element concentrations, REE spectra, glauconite compositions and siderite contents. This implies that remobilisation is restricted to intra-strata processes, rather than between strata. Modelling of the injected part of the field is therefore likely to be comparable to that of the in situ parts, as the original composition of the sand is the same.
ICP-MS and CCSEM have proved useful in characterising sand types, and from these observations it was possible to identify the origin of the intrusive sand bodies. Especially the REE spectra measured by ICP-MS and the glauconite compositions measured by CCSEM have enhanced the understanding of the sediments.

\section{Acknowledgements}

This study was conducted in cooperation with the partnership of Licence 4/95 in the Danish North Sea, operated by DONG Energy. The partnership is thanked for permission to publish the results.

\section{References}

Boynton, W.V. 1984: Geochemistry of the rare earth elements: meteorite studies. In: Henderson, P. (ed.): Rare earth element geochemistry, 63-114. Amsterdam: Elsevier.

Friis, H., Poulsen, M.L.K., Svendsen, J.B. \& Hamberg, L. 2007: Discrimination of density flow deposits using elemental geochemistry - implications for subtle provenance differentiation in a narrow submarine canyon, Palaeogene, Danish North Sea. Marine and Petroleum Geology 24, 221-235.

Hamberg, L., Dam, G., Wilhelmson, C. \& Ottesen, T.G. 2005: Paleocene deep-marine sandstone plays in the Siri Canyon offshore Denmark, southern Norway. In: Doré, A.G. \& Vining, B.A. (eds): Petroleum geology: North-West Europe and global perspectives, 1185-1198. Proceedings of the 6th Petroleum Geology Conference. London: Geological Society.

Keulen, N., Frei, D., Bernstein, S., Hutchison, M.T., Knudsen, C. \& Jensen, L. 2008: Fully automated analysis of grain chemistry, size and morphology by CCSEM: examples from cement production and diamond exploration. Geological Survey of Denmark and Greenland Bulletin 15, 93-96.

Odin, G.S. \& Matter, A. 1981: De glauconiarum origine. Sedimentology 28, 611-641.

Poulsen, M.L.K., Friis, H., Svendsen, J.B., Jensen, C.B. \& Bruhn, R. 2007: The application of bulk rock geochemistry to reveal heavy mineral sorting and flow units in thick, massive gravity flow deposits, Siri Canyon Palaeocene sandstones, Danish North Sea. Developments in Sedimentology 58, 1099-1121.

Schiøler, P. et al. 2007: Lithostratigraphy of the Palaeogene - Lower Neogene succession of the Danish North Sea. Geological Survey of Denmark and Greenland Bulletin 12, 77 pp.

Weibel, R., Friis, H., Kazerouni, A.M., Svendsen, J.B., Stokkendal, J. \& Poulsen, M.L.K. 2010: Development of early diagenetic silica and quartz morphologies - examples from the Siri Canyon, Danish North Sea. Sedimentary Geology 228, 151-170.

\footnotetext{
Authors' addresses

M.O. \& C.K., Geological Survey of Denmark and Greenland, Øster Voldgade 10, DK-1350 Copenhagen K, Denmark. E-mail: mol@geus.dk

J.B.S., DONG Energy, Exploration and Production, Agern Allé 24-26, DK-2970 Horsholm, Denmark.
} 